\title{
A Study of College English Classroom Discourse
}

\author{
Xiaoqing Jiang \\ School of Foreign Languages, Qingdao University of Science and Technology, Qingdao, Shandong, China \\ Email: xiaoqingqust@163.com
}

\begin{abstract}
The present study focuses on college English classroom discourse. Through a detailed description and analysis of the collected data by referring to Sinclair and Coulthard's classroom discourse analysis model and Nina Spada, Maria Fröhlich, Patrick Allen's COLT scheme, the discourse patterns and features are made clear and on the basis of which a few strategies for college English teachers are put forward by the author so as to improve college English teaching and learning.
\end{abstract}

Index Terms — college English, classroom discourse, pattern, feature, strategy

\section{INTRODUCTION}

Discourse is defined as "the language in use" (Cook, 1989, P. 6) and discourse analysis is concerned with the "the analysis of language in use" (Brown and Yule, 1983, P.1). Discourse analysis refers to the study of the relationship between language and the contexts in which it is used. It involves looking at both language form and language function and includes the study of both spoken interaction and written texts. It identifies linguistic features that characterize different genres as well as social and cultural factors that aid in our interpretation and understanding of different texts and types of talk. The application of discourse analysis to second language teaching and learning can reveal much about how teachers can improve their teaching practices by investigating actual language use in the classroom, and how students can learn language through exposure to different types of discourse.

Classroom discourse analysis is an aspect of classroom process research, which is one way for teachers to monitor both the quantity and quality of students' output. By following a four-part process of Record-View-Transcribe-Analyze, second language teachers can use discourse analytic techniques to investigate the interaction patterns in their classrooms and to see how these patterns promote or hinder opportunities for learners to practice the target language. Since spoken language is "the medium by which much teaching takes place and in which students demonstrate to teachers much of what they have learned" (Cazden, 1988, P. 432), the present study focuses on spoken language rather than written language, and the context specified here is the college English classroom of non-English majors.

The present study focuses on college English classroom discourse. The data are collected in three college English classrooms of non-English majors at Qingdao University of Science and Technology. Through a detailed description and analysis of the collected data by referring to Sinclair and Coulthard's classroom discourse analysis model and Nina Spada, Maria Fröhlich, Patrick Allen's COLT (Communicative Orientation of Language Teaching) scheme, the discourse patterns and features are made clear and on the basis of which a few strategies for college English teachers are put forward by the author so as to improve college English teaching and learning.

\section{RELATE THEORY}

\section{A. Discourse Analysis}

Discourse analysis is concerned with the study of the relationship between language and the contexts in which it is used. It grew out of work in different disciplines in the 1960s and early 1970s, including linguistics, semiotics, psychology, anthropology and sociology.

In 1952, Zellig Harris - one of the founders of discourse analysis, published a paper with the title "Discourse Analysis" (Harris, 1952, quoted in McCarthy, 1991, P. 5) on the journal "Language", making the term known to people. In the 1960s, Dell Hymes (1964, quoted in McCarthy, 1991, P. 5) continued discourse studies and introduced a social perspective to the field of discourse analysis by analyzing speech in social settings. He edited "Language in culture and society" in 1964, in which "speaking form" was researched. The linguistic philosophers such as Austin(1962), Searle (1969) and Grice (1975) (quoted in McCarthy, 1991, P. 5) contributed to the tradition and promoted the study of language as a social action. They were concerned with the social function of the language which gave rise to the development of speech-act theory and the formulation of conversational maxims.

Discourse analysis was developing in the 1970s. The research subject included reference, context, topic and comment, cohesion and coherence, substitution, etc. Most influential works were: "Some Aspect of Text Grammar" (Van Dijk, 1972), "Text and Context" (Van Dijk, 1977), "The Thread of Discourse" (Grimes, 1975), "Cohesion in English" (Halliday, 1976), "Papers on Discourse" (Grimes, 1978), etc. More and more researchers concentrated on the study of discourse analysis and discourse analysis as a new discipline has come into being.

The 1980s was a prospering stage of discourse analysis. An academic journal called "Text" was founded by Van Dijk 
in 1981 which gave discourse analysis an academic field. In 1983 G. Brown and G. Yule co-authored "Discourse Analysis", summarizing the previous research. In 1985 Van Dijk edited and published "Handbook of Discourse Analysis" which was regarded as a mark that discourse analysis was becoming an independent discipline.

\section{B. Sinclair and Coulthard's Model}

Sinclair and Coulthard (1975) developed a model for the description of teacher-pupil talk based on a hierarchy of discourse units. The Sinclair and Coulthard model was devised in 1975 and slightly revised in 1992. It consists of five ranks: lesson; transaction; exchange; move and act. The ranks are hierarchical in nature with lesson being the largest unit and act being the smallest as is shown in figure 1.

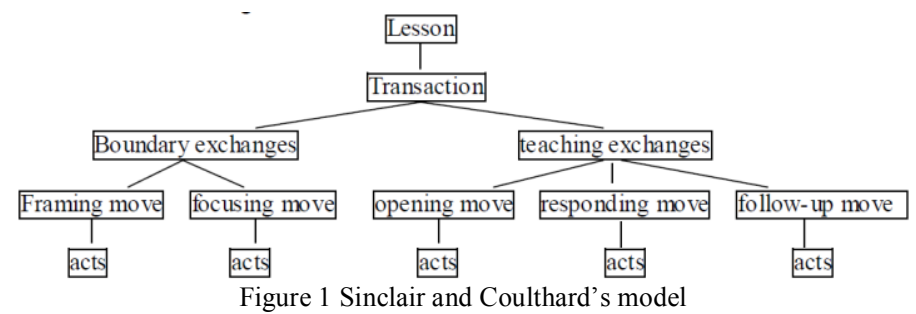

The highest rank "lesson" can't be structured according to "transaction", namely, the structure of "lesson" hasn't been found yet (Wang Dexing, 1998). "Transaction" is composed of "exchange", and is clearly structured. The boundary of transaction is marked by the words like OK, well, right, now and good which are usually stressed; have a falling tone and with a short pause. These words are referred to as "frame". A teacher tends to use a metastatement after a frame to indicate the beginning of a transaction and when a transaction is finished, another metastatement is used as conclusion. This kind of metastatement is called "focus", for example:

1) frame: Now,

focus: I want to tell you about a king who lived a long time ago in Ancient Egypt.

2) focus: What we've just done, what we've just done is given some energy to this pen. frame: Now,

The exchange which is made up of a frame and a focus is called "boundary exchange". The structure of a transaction begins with a boundary exchange and followed by a sequence of informing exchange, directing exchange or eliciting exchange, etc, which constitute "teaching exchange". A transaction is often ended by a boundary exchange too.

An "exchange" is composed of "moves" and has its own structure. Boundary exchange is composed of framing move and focusing move. Teaching exchange consists of opening move, responding move and follow-up move. For example:

3) T: Can you tell me why do you eat all that food? Yes.

P: To keep you strong.

T: To keep you strong. Yes. To keep you strong. Why do you want to be strong?

In this example, there is a boundary in the middle of the teacher's second sentence. According to Sinclair, there are two moves here, that is focusing move and opening move. Next example is an eliciting exchange:

4) T: Those letters have special names. Do you know what it is? What is one name that we give to these letters?

P: Vowels.

T: They're vowels, aren't they?

T: Do you think you could say that sentence without having vowels in it?

A huge amount of classroom discourse data like this example show that an eliciting exchange is made up of three moves and its structure is T-P-T. To put it in detail, that is, the teacher raises a question, then the students answer it, and the teacher gives an evaluative follow-up before raising another question. The three moves that constitute an eliciting exchange is referred to as "initiation", "response" and "follow-up". This kind of eliciting exchanges made up of the three moves is common in classrooms. When a student replies the teacher's question, the other students may not hear clearly sometimes. So the teacher needs to repeat the student's words so as to make it clear to all the students. What's more important is that the teacher should give "feedback" to the student's answer, to show whether the answer is right or whether it is the answer expected by the teacher. For example:

5) T: (elicit) What does the food give you?

P: (reply) Strength.

T: (feedback) Not only strength, we have another word for it.

P: (reply) Energy.

T: (feedback) Good, energy, yes.

In this kind of three-move structure if the third move doesn't appear, that usually is a hint that the student's reply is not correct. For example:

6) T: (elicit) Can you think why I changed "mat" to "rug"

P: (reply) Mat's got two vowels in it.

T: (feedback) 
T: (elicit) Which are they? What are they?

P: (reply) "a" and " $t$ "

T: (feedback)

T: (elicit) Is " $t$ " a vowel?

P: (reply) No.

T: (feedback) No.

A "move" is formed by one or many "acts", and also has its structure. The concept of "act" put forward here by Sinclair et al is different from the theory of "speech act" by Austin and Searl who aimed to find out how people do things with words, or to identify the pragmalinguistic features that native and/or non-native speakers employ to achieve their communicative goals in various speech events (Hinkel, 1997). Sinclair and Coulthard (1992) provide a definition of the discourse act: "Discourse acts are typically one free clause, plus any subordinate clauses, but there are certain closed classes where we can specify almost all the possible realizations which consist of single words or groups". The "act" here is defined and classified according to its exchange function. For instance, the function of elicitation act is to require a linguistic response and the function of informative act is to provide information. There are all together 22 acts put forward by Sinclair and Culthard (1975).

Sinclair and Coulthard also contributed a lot to the analysis of exchange structure. They found in the language of traditional native-speaker school classrooms a pattern of three-part exchanges, where the teacher made the initiation and the follow-up move, while pupils were restricted to responding moves (Coulthard, 1985, quoted in McCarthy, 1991). According to Coulthard (1985, quoted in Wang Dexing, 1998), an exchange is a structure made up of five moves:

$\mathrm{I}(\mathrm{R} / \mathrm{I}) \mathrm{R}(\mathrm{F})(\mathrm{F})$

An exchange is formed by at least two moves (initiation and response), and at most by five moves. Look at the following example:

7) T: Can anyone tell me what this means?

P: Does it mean danger men at work?

T: Yes...

(example 1-7 are quoted from Wang Dexing, 1998, P.202-209)

Here, P's words are not only a response to T's question, but also an initiation. In college English classrooms where the students have low proficiency, discourse acts such as "loop", "nomination", "prompt", and "clue" are expected to appear, because when a teacher does not get a response or gets a wrong answer to an elicitation, she/he can start again by repeating or rephrasing the question, or move on to another pupil. An discourse element for these teacher's acts is called 'bound initiation' (Ib), and it may be bound in ways of 're-initiation', 'listing', 'reinforce' or 'loop'. An exchange which reactivates an element in another exchange instead of repeating it or rephrasing it, is called 'bound exchange', contains single or a few Ib slots (Coulthard and Brazil, 1992).

In sum, the model of discourse analysis by Sinclair and Coulthard provide us with a set of description category and analysis procedures. This is undoubtedly a great contribution to discourse analysis. However, the Sinclair and Coulthard model is not without critics. It is far from perfect and is not quite applicable in describing natural discourse. Malouf (1995a, quoted in Andrew Atkins, 2001) argues that it "has only been applied to two-party discourse and would seem to fall short of the full range of linguistic communication." It has been modified by a number of scholars to account for less structured discourse patterns (Brazil and Coulthard, 1992, Coulthard, 1992; Farooq, 1999a, Francis and Hunston, 1992) such as telephone and casual conversations. The lack of an adequate description of intonation is another problem in Sinclair and Coulthard's model. The importance of intonation analysis in the pursuit of communicative purpose was also mentioned by Brazil (1995). Francis and Hunston (1992) point out one drawback that I have been careful to address in my data. Para-linguistic features such as gestures and eye-gaze may also be part of the discourse in face-to-face communication. I felt that recording the lesson on video might have had a negative effect on the naturalness of the discourse in classes of college English on campus. To avoid any negative effect, the lesson was recorded on cassette and para-linguistic items were not included in this study (as cited in Atkins, 2001).

\section{COLT Scheme}

COLT stands for "communicative Orientation of Language Teaching" and was introduced for the first time in 1984 by Nina Spada, Maria Fröhlich and Patrick Allen. This observation scheme was developed within the context of a project investigating the nature of L2 language proficiency and its development in classrooms, referred to as the Development of Bilingual Proficiency (DBP). One of the research components in this project was to investigate the effects of instructional variables on learning outcomes which required an observation scheme that could systematically describe instructional practices and procedures in different L2 classrooms. Furthermore, one of the main questions was whether instruction which was more or less communicatively oriented contributed differently to L2 development. An observation scheme was, therefore, needed to describe the exact features of instruction.

The COLT scheme is divided into two parts, the first of which describes classroom events at the level of episode and activity and the second part analyses the communicative features of verbal exchange between teachers and students and/or students and students. Thus it is quite suitable to explore the research questions mentioned above. In the description and analysis of the data, this scheme is frequently consulted with a few variations. 
In part A of the COLT scheme there are five categories: activity, participant organization, content, student modality and materials. "Activity" is open-ended; no predetermined descriptors have to be checked off by the observer. Each activity and its constituent episode are separately described and timed so that a calculation of the percentage of time spent on various COLT categories can be determined. "Participant organization" describes three basic patterns of organization: Whole class, Group work and individual seat work. The parameter of "content" describes the subject matter of the activities, that is, what the teacher and the students are talking, reading, or writing about or what they are listening to. Three major content areas have been differentiated along with the category Topic Control: management, explicit focus on language, and other topics which refers to the subject matter of classroom discourse, apart from management and explicit focus on language. Topic control indicates who selects the topic that is being talked about - the teacher, the student, or both. "Student modality" identifies the various skills involved in a classroom activity with the focus on the students and the purpose to discover whether they are listening, speaking, reading, or writing or whether these activities are occurring in combination. The category "Other" covers such activities as drawing, acting, etc. "Material" describes the materials used in connection with classroom activities. As the present study takes spoken discourse as the research field, the category of "material" is not included in this study.

Part B of COLT analyses communicative features of verbal exchange and is divided into teacher verbal interaction and student verbal interaction. As the present study deals with both teachers' and students' discourse, the two parts were all included in the description. There are 7 categories in this part: use of target language; information gap; sustained speech; reaction to code or message; incorporation of preceding utterances; discourse initiation; and relative restriction of linguistic form. The original COLT scheme has two alternatives in "use of target language"-first language (L1) or second language (L2). A third alternative is desirable in this study, however, namely translation. Since target language is meant to show how often the teachers and students trying in their second language instead of using their first language, situations where students are demanded to do translation work both from L1 to L2 and from L2 to L1 cannot be included in these counts. The feature of "information gap" refers to the extent to which the information requested and/or exchanged is unpredictable, i.e., not known in advance. "Sustained speech" is intended to measure the extent to which speakers engage in extended discourse or restrict their utterances to a minimal length of one sentence, clause or word. To measure amount of speech, COLT includes three categories: ultraminimal, minimal and sustained, where sustained speech consists of at least three main clauses. The present study, however, indicated that this division was too wide. Very few student utterances could be regarded as sustained speech. The categories used in this study were with some adaptation: ultraminimal, (utterances consisting of one or two words), minimal speech (phrase, clause), and sustained speech (at least one main clause with extension). "Reaction to code or message" refers to a correction or other explicit statement which draws attention to the linguistic form of an utterance. "Incorporation of preceding utterances" shows the way teacher gives feedback such as no incorporation, repetition, paraphrase, comment, expansion and elaboration. "Discourse initiation" measures the frequency of self-initiated turns by students. As this is very rare in the college English classrooms observed, this category is also excluded in the present study. It has been argued that a creative and uncontrolled language use, just like the one in L1 development, is also crucial in classroom language learning. "Form restriction" measures this dimension. COLT scheme differentiates in restricted use, limited use and unrestricted use.

Part B is analyzed according to these different categories from the aspects of teacher verbal instruction and students verbal interaction respectively.

\section{DATA ANALYSIS AND DiSCUSSION}

\section{A. College English Classroom Discourse Patterns}

\section{Analysis of the classroom discourse for TPT structure}

The recorded discourse was transcribed and analyzed using the Sinclair and Coulthard's 'IRF' (Initiation-Response-Feedback) model for an exchange, a move and an act (1975). A total of 271 exchanges consisting of about 1150 utterances were identified.

The results of discourse structure analysis for Teacher-Pupil-Teacher (TPT) sequences are shown in Table 1.

TABLE 1

AN ANALYSIS OF THE CLASSROOM DISCOURSE FOR TPT STRUCTURE CLASS ONE

\begin{tabular}{||l|l|l||}
\hline \hline T-initiate & Number of exchanges & $98.02 \%$ \\
\hline P-initiate & Number of exchanges & $1.98 \%$ \\
\hline T & 11 & $10.89 \%$ \\
\hline TP & 32 & $31.68 \%$ \\
\hline TPT & 41 & $40.59 \%$ \\
\hline TPTP & 11 & $10.89 \%$ \\
\hline TPTPT & 4 & $3.96 \%$ \\
\hline PT & 2 & $1.98 \%$ \\
\hline PTP & 0 & 0 \\
\hline PTPT & 0 & 0 \\
\hline Total & 101 & $100 \%$ \\
\hline
\end{tabular}


Class TWO

\begin{tabular}{||l|l|l||}
\hline T-initiate & Number of exchanges & $86.02 \%$ \\
\hline P-initiate & Number of exchanges & $13.98 \%$ \\
\hline T & 22 & $23.66 \%$ \\
\hline TP & 7 & $7.53 \%$ \\
\hline TPT & 38 & $40.86 \%$ \\
\hline TPTP & 5 & $5.38 \%$ \\
\hline TPTPT & 8 & $8.60 \%$ \\
\hline PT & 9 & $9.68 \%$ \\
\hline PTP & 2 & $2.15 \%$ \\
\hline PTPT & 2 & $2.15 \%$ \\
\hline Total & 93 & $100 \%$ \\
\hline
\end{tabular}

ClASS THREE

\begin{tabular}{||l|l|l||}
\hline T-initiate & Number of exchanges & $100 \%$ \\
\hline P-initiate & Number of exchanges & $0 \%$ \\
\hline T & 21 & $27.27 \%$ \\
\hline TP & 5 & $6.49 \%$ \\
\hline TPT & 30 & $38.96 \%$ \\
\hline TPTP & 5 & $6.49 \%$ \\
\hline TPTPT & 16 & $20.78 \%$ \\
\hline PT & 0 & 0 \\
\hline PTP & 0 & 0 \\
\hline PTPT & 0 & 0 \\
\hline Total & 77 & $100 \%$ \\
\hline
\end{tabular}

TOTAL

\begin{tabular}{||l|l|l||}
\hline \hline T-initiate & Number of exchanges & $99.03 \%$ \\
\hline P-initiate & Number of exchanges & $0.96 \%$ \\
\hline T & 54 & $19.93 \%$ \\
\hline TP & 44 & $16.24 \%$ \\
\hline TPT & 109 & $40.22 \%$ \\
\hline TPTP & 21 & $7.75 \%$ \\
\hline TPTPT & 28 & $10.33 \%$ \\
\hline PT & 11 & $4.10 \%$ \\
\hline PTP & 2 & $0.74 \%$ \\
\hline PTPT & 2 & $0.74 \%$ \\
\hline Total & 271 & $100 \%$ \\
\hline
\end{tabular}

Abbreviations T: Teacher, P: Pupil

Sinclair and Coulthard (1975) found that a TPT sequence is a regular sequence in the classroom discourse. Table 1 shows that around $40.22 \%$ of the total exchanges analyzed had a TPT structure. TPT accounted for the largest proportion of all the exchanges in these three classes with class one $40.59 \%$, class two $40.86 \%$ and class three $38.96 \%$. The other structures observed included T, TP, TPTP, TPTPT, PT, PTP, PTPT. The most obvious and typical feature found in this table was that Teacher-initiated exchanges made up the overwhelming majority of the exchanges with a total number of $99.03 \%$, and in class 3, teacher-initiated exchanges even occupied $100 \%$.

With "TPT" and "T-initiated" exchanges dominating, the three classes all had their own distinctive features in exchange patterns.

In class one the second largest proportion of the exchanges was TP, which accounted for $31.86 \%$ maybe because the teacher explained many words to the students. After the explanation, the students would read the words and the teacher would go on with the next one without giving any feedback if the word was easy. For example:

8) I-1-T: the third word, hostile, means unfriendly (s).

R-2-PP: hostile (rep).

9) I-1-T: Next, isolate, isolate from sth (s).

R-2-PP: isolate (rep)

The pattern "PT" appeared in this class although there were only two exchanges accounting $1.98 \%$.

In class two and three, the second largest number was that of the pattern "T" which was $23.66 \%$ and $27.27 \%$ respectively. From the number and also from my observation, it was easily seen that the teacher in these two class spent quite a long time in explanation and interpretation of the text so as to ensure that most of the students could understand it completely. For example:

10) I-1-T: The text of section A is quite easy. In paragraph 1, the author gives us an introduction. And from paragraph 2 to the last paragraph the author gives us many examples to show the environmental problems and how the countries solve the problems (i).

11) I-1-T: Paragraph 2 tells us changes of all people's life. Besides children, adult life are also changed. In second line we have the word "enormous". Maybe you don't know the meaning but you can guess using the skill of "finding out word meanings" we learned just now. The buildings, apartment buildings are very high, they can hold a lot of 
people. So "enormous" means "huge", "very big" (i).

According to my own experience, in college English classrooms, such long monologue of the teachers are very common. It's not strange that the pattern of "T" had such a large proportion because the students' English is generally poor and one of the main aims of teaching is to inform the students of the meaning of the text and some important language points. The other reason is that the traditional teaching method is still prevailing in this university although reforms is being seriously considered and is in its infancy to be implemented in classrooms.

In class two, the pupil-initiated exchanges made up $13.98 \%$ of all the exchanges, which is much more than that of the other two classes even though the number was small itself. An activity in this class was that the teacher asked the students to find out some key words and nominated some students to read them and explain them. For example:

12) 1-P1: Paragraph 6, decade (i).

2-T: Yeah, "for decades" (acc). A decade is ten years (i).

13) 1-P1: The first is in line 4 (i)

2-T: line 4(acc).

3-P1: "pocket". It means area here (i).

4-T: Yeah, very good. Line 4, "in various pockets of the world", here "pocket" means areas (acc/eva).

In class three, the pattern "TPTPT" occupied the third largest proportion of the exchanges which showed that the teacher was trying to make the students talk more in class. For example:

14) I-1-T: OK, tell me your choice, and tell me why you make the choice (m/el).

R-2-P1: A (rep).

F-3-T: Yes, very good (acc/com). Why do you choose A? (el)

R-4-P1: because of the word "choice" (rep).

F-4-T: Yes, choice is the synonym of "option", very good! (acc/com)

2. Analysis of the classroom discourse using the 'IRF' model

The results of discourse structure analysis using Sinclair and Coulthard's Initiation-Response-Feedback (IRF) model are shown in Table 2.

TABLE 2

AN ANALYSIS OF THE CLASSROOM DISCOURSE FOR IRF STRUCTURE

\begin{tabular}{|l|l|l|l|l|l|l|l|l||}
\hline \multirow{2}{*}{$\begin{array}{l}\text { Discourse } \\
\text { element }\end{array}$} & \multicolumn{2}{|l|}{ Class one } & \multicolumn{2}{|l|}{ Class two } & \multicolumn{2}{l|}{ Class three } & \multicolumn{2}{l|}{ Total } \\
\cline { 2 - 10 } & $\mathrm{N}$ & $\%$ & $\mathrm{~N}$ & $\%$ & $\mathrm{~N}$ & $\%$ & $\mathrm{~N}$ & $\%$ \\
\hline I & 11 & $10.89 \%$ & 22 & $23.66 \%$ & 21 & $27.27 \%$ & 54 & $19.93 \%$ \\
\hline I R & 32 & $31.68 \%$ & 7 & $7.53 \%$ & 5 & $6.49 \%$ & 44 & $16.24 \%$ \\
\hline I R F & 38 & $37.62 \%$ & 34 & $36.60 \%$ & 27 & $35.06 \%$ & 99 & $36.53 \%$ \\
\hline I R F R & 3 & $2.97 \%$ & 1 & $1.08 \%$ & 1 & $1.30 \%$ & 5 & $1.85 \%$ \\
\hline I R Ib R & 1 & $0.99 \%$ & 2 & $2.15 \%$ & 0 & 0 & 3 & $1.11 \%$ \\
\hline I R Ib R F & 3 & $2.97 \%$ & 2 & $2.15 \%$ & 9 & $11.69 \%$ & 14 & $5.17 \%$ \\
\hline I Ib R F & 1 & $0.99 \%$ & 2 & $2.15 \%$ & 1 & $1.30 \%$ & 4 & $1.48 \%$ \\
\hline I Ib Ib R F & 0 & 0 & 1 & $1.08 \%$ & 2 & $2.60 \%$ & 3 & $1.11 \%$ \\
\hline I R F/I R F & 8 & $7.92 \%$ & 5 & $5.38 \%$ & 6 & $7.79 \%$ & 19 & $7.01 \%$ \\
\hline Other & 4 & $3.96 \%$ & 17 & $18.28 \%$ & 5 & $6.49 \%$ & 26 & $9.59 \%$ \\
\hline Total & 101 & $100 \%$ & 93 & $100 \%$ & 77 & $100 \%$ & 271 & $100 \%$ \\
\hline
\end{tabular}

The discourse analysis by Sinclair and Coulthard (1975) is for classroom situations where the teacher exerts the maximum amount of control over the structure of the discourse (Sinclair and Coulthard, 1975; Coulthard, 1985; quoted in McCarthy, 1991). Table 2 shows that there were some features observed which agreed with Sinclair and Coulthard's findings on discourse structure, for example, IRF (36.53\%), I (19.93\%) and IR (16.24\%) were observed at relatively high rates just as Table 1 shows that the teacher-initiated exchange was dominant $(99.03 \%)$. This is probably because: (1) the classes examined in this study were all large classes of about 70 students where the students were in formal or restrictive circumstances. The teachers exerted the maximum amount of control over the classes and the structures of the discourse. (2) Chinese students have been disciplined not to speak in classes without a teacher's direction, the attitude of Chinese students towards speaking English in front of other students are often negative because they fear making mistakes, and (3) the students simply cannot speak due to their poor English ability so they only spoke when they were asked to in most of the cases.

\section{B. College English Classroom Discourse Features}

COLT Scheme describes the communicative features of classroom discourse. The categories in COLT were employed to analyze the discourse features of teacher verbal instruction and student verbal interaction based on approximately 1150 utterances. Thus the discourse features in the present study would be analyzed and discussed in these two respects.

Table 3 adapted from COLT system showed the percentage of utterances on each category. 
TABLE 3

TEACHER VERBAL INSTRUCTION(\% OF CODED UTTERANCES)

\begin{tabular}{|c|c|c|c|c|c|c|c|c|c|c|c|c|c|}
\hline \multirow{2}{*}{$\begin{array}{l}\begin{array}{l}\text { Comm. } \\
\text { features }\end{array} \\
\text { Sub } \\
\text { categ. }\end{array}$} & \multicolumn{3}{|c|}{$\begin{array}{l}\text { Target } \\
\text { Lang. }\end{array}$} & \multicolumn{2}{|c|}{$\begin{array}{l}\text { Information } \\
\text { gap }\end{array}$} & \multicolumn{2}{|c|}{$\begin{array}{l}\text { Sust. } \\
\text { speech }\end{array}$} & \multicolumn{6}{|c|}{$\begin{array}{l}\text { Incorporation of } \\
\text { preceding utterance }\end{array}$} \\
\hline & L1 & Tr. & $\mathrm{L} 2$ & $\begin{array}{l}\text { Request } \\
\text { Genuine } \\
\text { Infor. }\end{array}$ & $\begin{array}{l}\text { Request } \\
\text { Pseudo } \\
\text { Infor. }\end{array}$ & Min. & Sust. & $\begin{array}{l}\text { No } \\
\text { Incorp. }\end{array}$ & Repet. & Paraphr. & Comm. & Expan. & Elab. \\
\hline Class 1 & 3.47 & 6.13 & 90.40 & 12.20 & 87.80 & 18.12 & 81.88 & 6.25 & 25.0 & 15.63 & 12.5 & 9.38 & 31.25 \\
\hline Class 2 & 5.61 & 9.44 & 84.95 & 14.29 & 85.71 & 13.91 & 86.09 & 2.94 & 26.47 & 17.65 & 14.71 & 8.82 & 29.41 \\
\hline Class 3 & 4.18 & 5.22 & 90.60 & 9.38 & 90.63 & 12.23 & 87.77 & 3.45 & 24.14 & 24.14 & 10.34 & 6.90 & 31.03 \\
\hline Total & 4.43 & 6.96 & 88.61 & 11.96 & 88.04 & 14.81 & 85.19 & 4.21 & 25.26 & 18.95 & 12.63 & 8.42 & 30.53 \\
\hline
\end{tabular}

TABLE 4

STUDENT VERBAL INTERACTION (\% OF CODED UTTERANCES)

\begin{tabular}{|c|c|c|c|c|c|c|c|c|c|c|c|}
\hline $\begin{array}{l}\text { Comm. } \\
\text { Features }\end{array}$ & \multicolumn{3}{|l|}{$\begin{array}{l}\text { Target } \\
\text { Lang. }\end{array}$} & \multicolumn{2}{|c|}{$\begin{array}{l}\text { Information } \\
\text { gap }\end{array}$} & \multicolumn{3}{|c|}{$\begin{array}{l}\text { Sust. } \\
\text { speech }\end{array}$} & \multicolumn{3}{|c|}{ Form restriction } \\
\hline $\begin{array}{l}\text { Sub } \\
\text { categ. }\end{array}$ & L1 & Tr. & $\mathrm{L} 2$ & $\begin{array}{l}\text { giving } \\
\text { unpred. } \\
\text { Infor. }\end{array}$ & $\begin{array}{l}\text { giving } \\
\text { pred. } \\
\text { Infor. }\end{array}$ & $\begin{array}{l}\text { Ultra } \\
\text { Min. }\end{array}$ & Min. & Sust. & Restr. & limited & Unrestr. \\
\hline Class1 & 3.66 & 10.53 & 86.32 & 6.25 & 93.75 & 57.78 & 26.67 & 15.56 & 55.29 & 27.06 & 17.65 \\
\hline Class2 & 16.85 & 22.47 & 60.67 & 10.67 & 89.33 & 46.91 & 25.93 & 27.16 & 46.48 & 21.13 & 32.39 \\
\hline Class3 & 3.85 & 3.85 & 92.31 & 9.84 & 90.16 & 58.49 & 22.64 & 18.87 & 59.09 & 34.09 & 6.82 \\
\hline
\end{tabular}

The classroom activities concentrated on form more than on meaning with a percentage of 59.58\%; 1 Teachers dominated the class with $87.94 \%$ of topic control and requested much more pseudo information $(88.04 \%)$ than genuine information (11.96\%) and students even gave a $91.38 \%$ of predictable information, which meant that communication and interaction did exist in the classrooms observed but the communication between teacher and students was more of the pseudo-communication instead of real communication.

\section{CONCLUSION}

The findings of the study are summarized as follows:

The primary exchange patterns of college English classroom are T-P-T, and I-R-F. Other patterns like T, TP, TPTP, TPTPT, PT, PTP, PTPT, and I, I R F R, I R Ib R, I R Ib R F, I Ib R F, I Ib Ib R F, I R F/I R F also exist. The classroom discourse features are: classroom activities mainly center on form rather than meaning; language learning and practicing composes the primary content of teaching; whole class activities are much more than individual activities and group work has not been found in any of the classes; teacher dominates the class and controls the topic; language used in classroom is mostly English by both teacher and students; in most cases teacher's discourse is "sustained speech" while students' discourse largely belongs to "ultraminimal" or "minimal" with only words, phrases and short sentences; information requested by teacher and given by students is almost all pseudo and predicable. All these features imply that communication does exist in college English classrooms but it is far from natural.

Based on the study above, the following strategies are suggested: Asking "referential" questions and giving "facilitating" feedbacks; Involving more "negotiated interaction" in classroom discourse; Engaging the students in group work; Maximize opportunities for students participation. College English teachers can refer to these strategies for sustaining student engagement and communicative interaction in classroom for the purpose of improving college English teaching and learning. This is also the significance of the present study.

\section{REFERENCES}

[1] Cook, G. (1989). Discourse. Hong Kong: Oxford University Press.

[2] Brown, G \& Yule G (1983). Discourse Analysis [M]. London: Cambridge University Press.

[3] Cazden, (1988). Classroom discourse: the language of teaching and learning [M]. Portsmouth: Heinemann.

[4] Michael McCarthy, (1991). Discourse Analysis for Language Teachers. London: Cambridge University Press.

[5] Sinclair, J. and Coulthard, M. (1975). Towards an Analysis of Discourse. Oxford: Oxford University Press.

[6] Coulthard, M. (1992). Advances in spoken discourse analysis. London: Routledge

[7] Spada, N. \& M. Fröhlich. (1995). Communicative orientation of language teaching observation scheme. Coding conventions and applications. Sydney: NCELTR, Macquarie University.

[8] Andrew Atkins. (2001). Sinclair and Coulthard's "IRF" model in a one-to-one Classroom: an Analysis. [online] Available at: http://www.birmingham.ac.uk/Documents/college-artslaw/cels/essays/csdp/Atkins4.pdf

[9] Dexing Wang. (1998). English Discourse Analysis and intercultural Communication. Beijing Language and Culture University Press.

Xiaoqing Jiang was born in Qingdao, China in 1976. She received her M.A. degree in linguistics from Ocean University of China in 2005.

She is currently a lecturer in the college of foreign languages, Qingdao University of Science and Technology, Qingdao, China. Her research interests include applied linguistics and English language teaching. 